\title{
Cidades do medo: a catástrofe urbana em romances contemporâneos de língua inglesa e portuguesa
}

FERnANDA Gil Costa

Universidade de Lisboa

\begin{abstract}
RESUMO: NESTE ENSAIO SÃO ABORDADOS ROMANCES DE DOIS ESCRITORES AMERICANOS E UM DE UM ESCRITOR ANGOLANO, CUJO TEMA É A CATÁSTROFE URBANA E AS SUAS CONSEQUÊNCIAS PARA OS SOBREVIVENTES. NOS ROMANCES AMERICANOS, SOBRE O 11 DE SETEMBRO, SOBRESSAI A PREOCUPAÇÃO COM O EFEITO TRAUMÁTICO DA CATÁSTROFE E COM O COMPORTAMENTO DA VÍTIMA, E EVIDENCIA-SE UMA ATITUDE DE PERDA E NOSTALGIA REGRESSIVA. NO ROMANCE EM LÍNGUA PORTUGUESA NÃO HÁ LUGAR PARA A VITIMIZAÇÃO, JÁ QUE A CATÁSTROFE É OLHADA COMO OPORTUNIDADE, E A NOSTALGIA NÃO VISA ALTERAR O DESEJO DE FUTURO.
\end{abstract}

ABSTRACT: IN THIS ESSAY TWO AMERICAN NOVELS ARE FOCUSED IN WHICH THE 9/1 1 CATASTROPHE IN MANHATTAN IS THE MAIN TOPIC. THE CHARACTERS WHICH SURVIVED THE TRAGEDY GO THROUGH THE AFTERMATH AS TRAUMATIZED VICTIMS, HARDLY RECOVERING FROM INTENSE SUFFERING AND NOSTALGIA AND FINDING A NEW MEANING FOR LIFE. A THIRD NOVEL BY AN ANGOLAN WRITER ALSO DEALS WITH URBAN CATASTROPHE ALTHOUGH IN A DIFFERENT WAY. THE CHARACTERS CAREFULLY PLAN THE CATASTROPHE, WHICH CAN BE LOOKED AT AS AN INSURRECTION. THE TRAUMA OF PAST TIME IS NOT NOSTALGIC AND INSISTS IN UNVEILING THE CHARACTERS BOTH AS PERPETRATORS OF URBAN CHAOS AND VICTIMS OF SOCIAL INEQUALITY AND RACIAL DISCRIMINATION.

PALAVRAS-CHAVE: CATÁSTROFE URBANA, VIITIMA, TRAUMA, NOSTALGIA. KEYWORDS: CATASTROPHE, VICTIMIZATION, TRAUMA, NOSTALGIA. 
m 2005 Jonathan Safran Foer (SF), um jovem autor (nascido em 1977), e em 2007 Don DeLillo (DL), consagrado veterano da vida literária americana (nascido em 1936) publicaram Extremely loud and incredibly close e falling man, respectivamente, dois dos romances mais conhecidos sobre o 11 de Setembro de 2001. Essas duas obras inserem-se, naturalmente, na sequência torrencial de efeitos literários (de interesse variável) despoletada pelo ataque terrorista à Nova Iorque (ARAÚJO. 2008/09) e foram escolhidas para figurar neste ensaio por razões que se tornarão transparentes.

Por outro lado, autores de países de língua portuguesa que viveram a experiência colonial e pós-colonial, atentos ao crescimento da metrópole caótica, babélica e multi-racial nos espaços do antigo império, encenam histórias de grande complexidade e actualidade onde as questões da violência, do terror e da segurança aparecem iluminadas a partir de enfoques específicos, sublinhando o papel revolucionário, mais ou menos ingênuo, de certos surtos de insurreição e violência urbana no mundo menos ocidentalizado de África e da América do Sul.

O exemplo escolhido é O ano em que zumbi tomou o Rio (2002) de José Eduardo Agualusa (AL), situado no Rio de Janeiro das favelas, com personagens que colaboraram na reconstrução da jovem sociedade angolana, com ligações de alto nível à política e à esfera do poder em Luanda, e viveram também os últimos anos da guerra colonial portuguesa e da guerra civil angolana.

O ponto de partida é a convicção de que o romance sobre a violência, o medo e o desastre, sobretudo de causas humanas, se escreve hoje nas sociedades mais ocidentalizadas predominantemente da perspectiva da vítima traumatizada, acompanhando e desafiando a reflexão de filósofos e sociólogos sobre a tendência de legitimação de políticas crescentemente securitárias nas metrópoles. O contágio e a manipulação do medo (das vítimas reais ou potenciais) são inevitáveis à medida que os habitantes das cidades contemporâneas vão descobrindo a vulnerabilidade e a contingência de uma ideia de bem estar e segurança cujas raízes nunca foram efectivamente aprofundadas. O percurso pelas obras citadas evidenciará, pois, as estratégias comunicativas e afectivas que o romance tem vindo a ensaiar para iluminar a vítima do terror aleatório que, no caso específico do 11 de Setembro nas duas obras sobre o tema, nada tem a ver com o lugar de origem da violência, mas sim com o ponto de impacto, reagindo, por isso, com grande perplexidade e quase total passividade. 
Por outro lado, será igualmente destacado o caso em que a violência urbana não é olhada pela perspectiva da vítima, mas do seu autor e executante e da convicção da sua necessidade, focando por isso a sua origem, a exclusão social e a crença no papel libertário da insurreição. Além disso, o circuito paralelo da delinquência e do crime organizado que alimenta e contamina a luta contra a injustiça e a exclusão será necessariamente referido, uma vez que a estratégia comunicativa de Agualusa e o laço afectivo a que habitualmente atrai o leitor fundamentam uma focalização de narrativa múltipla em que a citação, a deslocação (e a surpresa) da visão contribuem para a incerteza dos resultados e para a relativização do seu valor.

Nas duas obras mencionadas sobre o 11 de Setembro de 2001 em Nova Iorque existem, apesar do tema comum, poucas semelhanças; porém, ambas constituem um testemunho iniludível do efeito da catástrofe urbana sobre o imaginário e a criatividade de autores contemporâneos de várias gerações. Se tentarmos esboçar uma breve resenha sobre o que distingue os romances de DL e SF poderemos sublinhar que o último escolhe um herói juvenil de nove anos (um anti-herói, portanto), caso típico de narrador não credível, mas capaz de ganhar a empatia do leitor; recorre à inclusão de imagens no texto e dirige a atenção do leitor, através de analepses de personagens secundárias (a avó e, sobretudo, o avô) para a destruição apocalíptica do espaço urbano durante os bombardeamentos aéreos da Segunda Guerra Mundial, construindo uma ponte inesperada entre a história e a memória europeia do século XX e $\mathrm{o}$ ataque terrorista a Nova Iorque no início do século XXI.

A Segunda Guerra Mundial surge de algum modo como a origem remota, e inevitável do mal na sociedade contemporânea. A pós-memória adquire assim um papel decisivo e inesperado (M. Hirsch, 2008), já que o escritor pertence à geração dos que receberam e reescreveram o testemunho, embora as personagens que o encarnam sejam encenadas como meros sobreviventes.

No romance de DL encontramos um sobrevivente do ataque ao World Trade Center que, apesar da dificuldade em lidar com o "depois" do evento, refaz de forma inesperada a sua vida, em várias etapas, começando pelo regresso à vida em comum com a ex-mulher e o filho de ambos. Entre as personagens secundárias encontramos uma amante também sobrevivente do desastre, pacientes que sofrem de doenças degenerativas, um ex-terrorista dos grupos europeus de extrema esquerda dos anos setenta e oitenta (um pro- 
tótipo), o grupo dos terroristas do 11 de Setembro (de novo, um protótipo) e um artista-performer - o "homem em queda", que dá título ao romance. Este é a novidade, já que não chega a ser uma personagem, aproximando-se do funcionamento do motivo diegético. Fala-se sobre ele, especula-se sobre a sua história pessoal e chega a ser uma obsessão para a personagem principal que assiste involuntariamente às suas performances, mas não tem, ele mesmo, acesso à palavra; enquanto todas as outras personagens secundárias representam padrões, é o performer que cria uma espécie de síntese e epifania das consequências do desastre, seja no plano literal (o das imagens de Richard Drew, dos noticiários, dos documentários sobre as vítimas que se atiraram das Torres) seja no plano simbólico, em que a repetição do acto, através da encenação e performance da queda, se torna também um emblema do trauma, caracterizado pela repetição compulsiva e alucinatória de acontecimentos experienciados.

Com excepção desta última personagem que existe de certo modo fora da cena, todas as personagens envolvidas são em maior ou menor grau vítimas do acontecimento central. O próprio performer está presente para encarnar simbolicamente o evento singular que une o universo da diegese, já que o seu número é o "homem em queda", síntese das consequências do desastre e "mise en abyme" da condição degenerada de uma sociedade apocalíptica (a "Torre" pode adquirir também um sentido esotérico na sequência da indexação da personagem ao Tarot - COSTA, 2010), em que o desastre surge como previsão de queda e fim dos tempos (ou regeneração e nova oportunidade). Embora tenha nome próprio, o acrobata surge sempre em espaços públicos do tipo que Marc Augé descreveu como Não-lugares por não terem marcas antropológicas, identitárias e relacionais (AUGÉ, 1992); os seus números são executados em átrios de hotéis, em viadutos e estações de comboios. O nãolugar expõe de certo modo o anonimato das vítimas e a irrelevância da identidade perante o desastre.

Voltando a Extremely loud and incredibly close o herói é uma criança a braços com o trabalho de luto pelo pai, que se encontrava num dos últimos andares da Torre Sul no momento do embate do primeiro avião, uma das vítimas do ataque terrorista. Perante a ineficácia das cerimónias lutuosas, o enterro do caixão vazio descrito no primeiro capítulo, o pequeno Oskar persegue a memória do pai em busca de um desconhecido de nome Black e de uma 
fechadura para a chave guardada num envelope. A narração homodiegética é fundamentalmente assegurada por Oskar (este nome, o tambor que frequentemente usa, bem como o gosto pela percussão parecem uma alusão ao Oskar Matzerath de Die Blechtrommel, de Günter Grass), voz simultaneamente infantil, vulnerável, mas desconcertantemente lúcida (Oskar é claramente sobredotado, habituado pelo pai à reflexão através de passatempos instrutivos que visam a descoberta de mistérios a partir de pistas. A visão hegemónica de Oskar, apesar de não inteiramente fiável, desenha uma estratégia que impede o leitor de saber mais do que o herói antes das revelações finais.

Os outros narradores de primeira pessoa são os avós paternos de Oskar (oriundos de Dresden) que através das narrativas epistolares e diarísticas que escrevem ao neto (no caso da avó) e ao filho Thomas, vítima do ataque de 11 de Setembro (no caso do avô), inserem no romance a memória da Segunda Guerra Mundial e dos seus traumas individuais, construindo a ponte entre a sua memória dolorosa e a vivência do neto. Característico da estratégia comunicativa do romance é também o jogo com a mancha gráfica irregular da obra (há páginas numeradas em branco, outras com uma frase ou algumas palavras) e com a interposição de imagens que se funcionalizam e literalizam no texto verbal. As interrupções da escrita parecem criar um campo visual para fazer sobressair a consciente afasia do avô de Oskar, vítima dos bombardeamentos de Dresden, que regressa depois da morte do filho no ataque ao World Trade Center. A memória traumática da guerra despoletou no passado a hostilidade à integração social: recusa de ligações afectivas e de comunicação oral.

Oskar recupera a presença do avô, antes ainda do seu inesperado regresso, usando uma forma mediatizada de comunicação com a avó, que mora em frente na mesma rua, com quem fala através de linguagem gestual pela janela ou por hawkie-talkies. Além disso, ilustra com frequência as suas descobertas com as fotografias que tira com a máquina deixada pelo avô. A presença mais emblemática no uso da fotografia é a do "homem em queda", com a particularidade de as imagens aparecerem no final do romance como conjunto de instantâneos rebobinados, sendo a última a que capta a Torre no momento anterior ao início da queda do homem. Esta ilustração da previsível, progressiva cura de Oskar pelo trabalho de luto ocorre depois do último capítulo e de mais um período de insónia em que revê à luz da lanterna as suas colecções de relíquias intituladas "Stuff That Happened to Me"; depara 
então com recortes das fotografias do "homem em queda". O seu esforço para abandonar a hipótese de o pai ter sido um dos suicidas da Torre revela-se no esforço de narrar a história do fim para o princípio, como na inversão dos instantâneos da queda: "He would've walked backward to the subway, and the subway would've gone backward through the tunnel, back to our stop" (FOER, 2005:326).

O mais original neste processo de narração é a complementaridade entre o texto verbal e o das imagens no sentido de ampliar e multiplicar a visão subjectiva da primeira pessoa com uma espécie de perspectiva de câmara, semelhante a uma visão de terceira pessoa, sem pretender introduzir a chamada (e hoje muito contestada) visão omnisciente, que neste caso se revela impossível ou mesmo impraticável.

Em $O$ ano em que Zumbi tomou o Rio o angolano AL inventa uma (improvável!) ligação transatlântica entre a elite ex-militar que envolve o poder em Luanda e a rebelião alegadamente emancipadora de alguns chefes do narco-tráfico das favelas dos morros do Rio. Tomando a lenda e a história de Zumbi dos Palmares como fonte e inspiração, o africano que liderou com algum sucesso no Brasil, no Quilombo dos Palmares, a primeira insurreição anti-esclavagista, o autor capta uma imagem metropolitana do Rio de Janeiro que é subsidiária da de Nova Iorque nos dias que se seguiram ao ataque ao World Trade Center. No entanto, o ponto de focagem não ilumina vítimas dos acontecimentos, mas sim os seus autores, os narco-traficantes-rebeldes e o Coronel angolano Francisco Palmares que faz contrabando de armas (à revelia do governo de Luanda), acabando envolvido na causa dos insurrectos (o apelido Palmares não é acidental).

A obra revela, através da narração crua de acontecimentos (ocorridos durante a guerra civil angolana, ou nos ataques à favela em que balas perdidas atingem meninos vestidos de anjo antes de participar na procissão) e de diálogos entre personagens (entre Francisco e Monte, o torcionário do regime de Luanda que será contratado para assassinar o primeiro, sem sucesso), a visão entediada, descrente, desiludida, mas apesar de tudo ainda nostálgica ${ }^{1}$ do ex-

1. A palavra "nostalgia" é usada no contexto em oposição a "melancolia", no mesmo sentido em que Svetlana Boym afirma: "Unlike melancholia, which confines itself to the planes of individual consciousness, nostalgia is about the relationship between individual biography and the biography of groups or nations, between personal and collective memory" (BOYM, 2001:XVI). 
guerrilheiro e do ex-combatente que, perdidos os ideais à luz impiedosa da realidade pós-conflito, é incapaz de viver do contrabando de armas sem se incluir a si mesmo no negócio; Francisco abandonara Luanda para escapar ao Presidente cuja filha acredita estar morta por sua culpa, e termina no Morro da Barriga, ao lado do ex-chefe da polícia Jorge Velho (o nome é sintomaticamente o do executante de Zumbi), onde os últimos revoltosos se abrigam e barricam depois da reviravolta que os conduz à inevitável derrota no "lado errado da guerra" (AGUALUSA, 2002:16). Os pormenores da história são irrelevantes para o que aqui se pretende destacar. O efeito da tomada do Rio pelos herdeiros de Zumbi recai sobre os perpetradores e o olhar crítico incide sobre o grupo rebelde sem nunca o confundir com meras vítimas.

É pertinente notar que o romance em língua portuguesa parece soltar-se sem dificuldade (não só neste caso) da influente invasão da cultura de vitimização imposta nas últimas décadas, sobretudo pelo romance anglo-americano (que tem vindo a ser criticada por autoras como Elaine Showalter), destacando o maniqueísmo da abordagem a preto e branco; no romance de AL, os perpetradores são também derrotados e vítimas, destacando a origem do conflito, a revolta, a desigualdade social, o ressentimento racial. As vítimas traumatizadas, perdidas ou "em queda", não surgem na obra de AL. Pelo contrário, as personagens que mais desenvolvem uma estratégia empática com o leitor, Francisco Palmares, Anastácia - a amante de Jararaca (o narcotraficante, chefe dos revoltosos) e o jornalista-anão Euclides, cuja visão se confunde por vezes com a do narrador, embora vítimas casuais de evoluções aleatórias dos acontecimentos, nunca assumem estatuto de vítima.

No final, quando Euclides reencontra Anastácia em Budapeste, raptada e violada por Jacaré durante a tomada do Rio, no momento em que a dissidência marcara a divisão das forças rebeldes ainda vitoriosas, compara-a a um general "indiferente ao escândalo da própria glória”, e acrescenta: "Toda ela é triunfo (e leia-se aqui a palavra com o sentido que tinha na origem - triunfo: entrada solene e aparatosa dos generais vitoriosos na Roma antiga)" (AGUALUSA, 2002:250). É claro que não ignora o lado capcioso e superficial desse triunfo, pois repara nos cabelos brancos "tão tristes!" e numa "espécie de cansaço, ou de desengano, na forma como (Anastácia) fala do futuro" (Idem.:252). Também no seu caso se poderá falar de nostalgia, a saudade do futuro, e não de melancolia, o luto interminável pelo passado. 
Nas duas cenas que emolduram o romance ("O Fim, como se Fosse o Princípio" e "O Princípio como se Fosse o Fim”) encontramos a visão cíclica e nostálgica. Ao focar a curta distância os últimos momentos de Francisco Palmares e Jorge Velho barricados na favela, numa circularidade simultaneamente propiciatória e céptica, encontram-se ausentes quaisquer sinais de vitimização. Os dois homens falam da morte com humor e ironia, descrevem o céu como um lugar bendito de pequenos prazeres, ouvem musica, evocam Peter Pan.

Depois deste breve percurso por três romances sobre a metrópole contemporânea e a catástrofe, salientando abordagens tão distantes entre si, é possível, apesar de tudo, encontrar semelhanças com a nostalgia reflexiva descrita por Svetlana Boym (2001:49-55).

No romance de SF o herói juvenil, embora vítima de um trauma recente, escapa ao peso asfixiante do passado através de vários recursos diegéticos. É o caso das epístolas e diários do avô e da avó, que relativizam a sua experiência comparando-a com outras, e das aventuras a que se entrega, pois pressupõem que a resolução de um mistério pode abrir caminho ao futuro; é também o caso da experiência comunicativa gestual e não oral com o avô (por vezes com a avó) e sobretudo das imagens que são integradas como texto complementar e multi-dimensional, em especial as do "homem em queda" que no final regressa ao ponto de partida dentro da Torre, como um pássaro que levantasse voo. A variedade de formas de comunicação não verbal aponta para uma herança de saberes e práticas culturais (LEITE, 1998) que integram a memória performativa.

Em Falling man encontramos também, apesar de a narrativa parecer clássica na sua aparente prática de narração omnisciente, por vezes próxima do monólogo interior, a tentação do enigma como forma de desequilibrar a stasis aparentemente incontornável do "depois" da catástrofe. Keith, vítima sobrevivente do colapso das Torres, abandona a sua forma de vida anterior ao desastre não só regressando à ex-família, mas também recuperando o seu antigo passatempo, o jogo de poker, criando uma nova rotina, como se a única conclusão legítima fosse a aceitação da contingência e do acaso como leis soberanas da vida-jogo. Neste contexto, o performer David Janiak que se lança dos arranha-céus em queda livre, controlado apenas por um gancho que o suspende a poucos metros do chão, é um símbolo ambivalente do tempo de crise que oscila entre colapso e renovação. A carta do Tarot a que é explicita- 
mente indexado, o "Dependurado", remete justamente para essa duplicidade, a cabeça rodeada por uma auréola misteriosa prestes a tocar o chão. À sua maneira é uma espécie de anjo terrível - "um anjo em queda e possuía uma beleza horrenda" (DELILLO, 2006:228).

No romance de AL a incrustação da estória enquadrada, espécie de analepse entre dois momentos de uma cena (que distam entre si apenas vinte minutos), confere à narrativa interna um papel literalmente epifânico. Logo no início Francisco Palmares assiste à "ressurreição" do jornalista Euclides, a cujo enterro (encenado) assistira no passado, tal como mais tarde verá (contrariado) o regresso de Florzinha, que acreditara morta. A fronteira ténue e acidental entre vida e morte está sempre presente (Francisco tem como companhia doméstica uma tarântula de nome Rosa, mais um símbolo de ambivalência), a morte e a vida compram-se facilmente, sempre dependendo do acaso (no final sabe-se que o cadáver de Jararaca nunca apareceu, perturbando a polícia e enraízando o início da lenda), enquanto o motivo do anjo é também explicitado dentro e fora da favela. A última ligação de Francisco é com uma mulher conhecida por o Anjo Azul. Além disso, o texto da narrativa de mancha gráfica irregular, desdobra-se em citações, poesia, letras de música popular, por vezes rap de MV Bill, enquanto os títulos e subtítulos resumem ou empurram os acontecimentos.

Sendo o efeito de cada um dos romances, indiscutivelmente, singular, pode dizer-se que os três assumem um compromisso com a narrativa não convencional. Os recursos comunicacionais e as estratégias dirigidas à leitura ligamse ao uso de uma perspectiva múltipla, deslizante e descentrada, por vezes fragmentária, quase sempre infiável.

A principal diferença entre os romances sobre o 11 de Setembro e o de AL, apesar de semelhanças temáticas evidentes, tem a ver com a ligação dos primeiros à cultura da vitimização. Porém, é possível detectar o cuidado dos respectivos autores com a banalização dos estereótipos sobre o terror, com o maniqueísmo reinante em tempos de "estado de excepção" (AGAMBEM, 2005). Em Falling man a protagonista pensa sobre o companheiro da mãe, exmembro de um grupo terrorista europeu, nos termos seguintes: "Talvez ele fosse um terrorista, mas é um de nós, pensou, e este pensamento provocoulhe um calafrio, uma onda de vergonha - um de nós, o que queria dizer ateu, ocidental, branco" (DELILLO, 2006:200). A contradição e a fragmentação 
vivem, pois, no cerne da identidade descontínua, fraccionada. A história pessoal tem óbvios pontos de contacto com a história colectiva, as personagens vivem em lugares a que não pertencem naturalmente, cruzam lugares de origem com lugares de passagem e de vivência.

Svetlana Boym (2001:50) distingue entre a noção de nostalgia reflexiva e nostalgia restaurativa. Esta última, predominantemente ligada ao passado, de humor melancólico, prefere um tempo espacializado, refaz o culto dos lugares e dos objectos a que confere poder representativo e durabilidade. A nostalgia reflexiva, ao contrário, tende a transformar o espaço em tempo, viaja com a memória a tiracolo, a casa de origem está sempre (com outras) na casa em que habita, é presente (embora seja ao mesmo tempo passado e futuro).

Parece óbvio que estas duas espécies de nostalgia se complementam. Francisco Palmares é uma encarnação quase perfeita da nostalgia reflexiva já que o ritmo apressado desfaz o espaço da experiência, episódio atrás de episódio, país atrás de país (Portugal, Angola, Brasil), cidade atrás de cidade (Lisboa, Luanda, Rio), a memória individual disseminada, partilhada com a colectiva, a história pessoal entrelaçada na história da língua, das nações, das raças. Como afirma Homi Bhabha em The location of culture:

O pedagógico encontra a sua autoridade narrativa na tradição do povo, (...). O performativo intervém na soberania da autogeração da nação, ao lançar uma sombra entre o povo como 'imagem' e o seu significado enquanto signo diferenciador do Eu, distinto do Outro ou do Exterior (apud BUESCU, 2001:543).

Ora, as personagens de $O$ ano em que Zumbi tomou o Rio carregam na vivência dos dias de insurreição a história pedagógica da nação (colonial, africana, oral) e a experiência pós-colonial da libertação e da independência, o duplo olhar, a "escrita-dupla ou dissemi-nação" e, por isso, são simultaneamente agentes e efeitos de acontecimentos prévios, o passado participando como fantasma no presente (Zumbi, Jorge Velho, a guerra civil), pagando o preço da alienação e do jogo simbólico do poder que Jorge Velho implicitamente reconhece na primeira cena, quando resume a situação para Francisco: "Não é o lado errado da guerra, Coronel. É apenas o que vai perder" (AGUALUSA, 2002:16). Numa intervenção relativamente recente, em Lisboa, Bhabha afirmou: 
Ao contrário do que acontece com o futuro, não podemos 'escolher' o nosso passado cultural ou biográfico; podemos esquecê-lo num gesto de amnésia histórica; podemos reconstruí-lo de modo a que se adéque aos nossos interesses presentes; ou podemos condensá-lo no presente, a fim de demonstrar a continuidade da tradição cultural como parte da confluência de uma história partilhada. Em cada um destes casos, negociamos com o 'passado' para transformar as nossas vidas; (...) o passado torna-se 'nós', tal como o futuro nos toma" (BHABHA, 2007:29-30).

O espaço das cidades do desastre e do medo liga de forma especial a biografia e o colectivo, a memória e a nostalgia do futuro porque o momento a que se chama presente, quando preso na teia obsessiva da catástrofe parece deixar de ser a confluência do que passou e do por-vir, prende o tempo numa vertigem interminável, torna-se narrativa cíclica em que princípio e fim se misturam, em instantes a desdobrar (ainda que num jogo) para trás ou para a frente, repete o desastre numa rememoração descontrolada ou enfrenta a morte (mas não o fim) como uma viagem ou salto para fóra do tempo linear.

\section{Referências Bibliográficas}

AGAMBEM, Giorgio. State of Exception, Chicago, Ch. University Press, 2005.

AGUALUSA, José Eduardo. O Ano em que Zumbi Tomou o Rio. Lisboa: Dom Quixote. 2002 .

ARAÚJO, Susana. "Security Unlocked and Fictions of Terror", in Review Of International American Studies (RLAS), vol. 3. 3-4. 1. 2008/2009, pp. 5-14.

AUGÉ, Marc. Não-Lugares. Introdução a uma Antropologia da Sobre-modernidade, Lisboa: 90 Graus. 2005 (1992).

BHABHA, Homi. "Ética e Estética do Globalismo: Uma Perspectiva Pós-Colonial", in A Urgência da Teoria. O Estado do Mundo. Lisboa: Fundação Calouste Gulbenkian e Tinta da China. 2007, pp. 21-44.

BOYM, Svetlana. The Future of Nostalgia. New York: Basic Books. 2001.

COSTA, Fernanda Gil. "Entre Realismo e Esoterismo: O romance de Don DeLillo 'Falling Man', in Livro de Homenagem à Professora Ivete Centeno. (2009), no prelo.

DELILLO, Don. Falling Man. London: Picador. 2007 (tradução portuguesa de Paulo Faria. O Homem em Queda, Lisboa: Sextante Ed. 2007). 
BUESCU, H. et alii (orgs.) Floresta encantada. Novos Caminhos da Literatura Comparada. Lisboa: Dom Quixote. 2001.

FOER, Jonathan Safran, Extremely Loud \& Incredibly Close. New York: Mariner Books. 2006 (2005).

HIRSCH, Marianne. "The Generation of Postmemory". In: Poetics Today. March 1, 2008; 29 (1), 103 -128.

LEITE, Ana Mafalda. Oralidades \& Escritas nas Literaturas Africanas. Lisboa: Colibri. 1998.

SHOWALTER, Elaine. Hystories: Hysterical Epidemics and Modern Media. New York: Columbia university Press. 1997.

Recebido em 05 de abril e aprovado em 11 de maio de 2010. 